\title{
Construction of a BAC library for buckwheat genome research - An application to positional cloning of agriculturally valuable traits -
}

\author{
Yasuo Yasui ${ }^{1}$, Masashi Mori ${ }^{2}$, Daiki Matsumoto ${ }^{1}$, Ohmi Ohnishi ${ }^{1}$, \\ Clayton G. Campbell ${ }^{3}$ and Tatsuya $\mathrm{Ota}^{4 *}$ \\ ${ }^{1}$ Laboratory of Crop Evolution, Graduate School of Agriculture, Kyoto University, Oiwake-cho, \\ Kitashirakawa, Sakyo-ku, Kyoto, 606-8502, Japan \\ ${ }^{2}$ Laboratory of Plant Gene Technology, Research Institute for Bioresources and \\ Biotechnology, Ishikawa Prefectural University, Suematsu \\ 1-308, Nonoichi, 921-8836, Japan \\ ${ }^{3}$ Kade Research Ltd., 126 Southpark Street, Morden, MB R6M 1H1, Canada \\ ${ }^{4}$ Department of Evolutionary Studies of Biosystems, The Graduate \\ University for Advanced Studies, Kamiyamaguchi \\ 1560-35, Hayama, 240-0193, Japan
}

(Received 14 May 2008, accepted 19 September 2008)

We have constructed a BAC library for common buckwheat Fagopyrum esculentum Moench. The library includes 142,005 clones with an average insert size of $~ 76$ $\mathrm{kb}$, equivalent to approximately a 7 8-fold coverage of the genome. Polymerase chain reaction based screening of the library with AGAMOUS and FLORICAULA/ $L E A F Y$ primers, has identified 7 and $9 \mathrm{BACs}$, respectively, which are consistent with the genome coverage. This library represents the first large insert genomic library for $F$. esculentum and it can be served as a genetic resource facilitating agricultural, pharmacological, physiological, and evolutionary studies of the species. To demonstrate the utilization of the library for characterizing agriculturally valuable traits, we developed a sequence tagged site marker tightly linked to the dwarf $E$ locus as well as to the self-incompatibility complex locus and screened the library to initiate positional cloning of the causative genes.

Key words: BAC library, buckwheat, dwarf, positional cloning, self-incompatibility

\section{INTRODUCTION}

Common buckwheat, Fagopyrum esculentum Moench, is an annual crop important in the temperate regions of the world. Unique features, such as tolerance to a wide range of environments and susceptibility to a limited number of diseases, have granted the species worldwide importance. In addition to being an edible resource, buckwheat contains biochemical compounds of pharmacological or medical interest (e.g., Fujimura et al., 2003; Kawa et al., 2003; Park and Ohba, 2004; Pu et al., 2004) and recent studies demonstrate some promise of its application in weed or soil management by utilizing the allelopathic effect of buckwheat (Tsuzuki and Dong, 2003) or it's ability to detoxify soil polluted with aluminum (Ma et al., 1997).

In spite of the difficulty in establishing isogenic lines in

Edited by Yoshio Sano

* Corresponding author. E-mail: ota@soken.ac.jp buckwheat for breeding purposes, owing to it's intrinsic heteromorphic self-incompatibility system, genetic research has been progressed due to its rapid maturity and the authors have been engaged in the development of public resources, such as genetic maps of morphological and protein markers (Ohnishi and Ohta, 1987) and of amplified fragment length polymorphism (AFLP) markers (Yasui et al., 2004). We have also constructed a simple sequence repeat (SSR) marker system (Konishi et al., 2006) and generated a SSR map for buckwheat (Konishi and Ohnishi, 2006). To further enrich genetic resources of buckwheat, we have constructed a bacterial artificial chromosome (BAC) library as reported herein. In many species a large insert genomic library, such as BAC, P1 artificial chromosome (PAC) or transformation competent artificial chromosome (TAC), has been indispensable, not only for genome analyses and functional studies of genes of interest but also for studying the evolution of genome or genetic systems of organisms. Notably, buckwheat belongs to Polygonaceae, one of the core tricolpates that 
diverged from other major tricolpates (e.g. rosids, asterids) at an early stage in angiosperm evolution (e.g. Judd et al., 1999), and buckwheat genomic library would be served as a useful resource for the study of plant genome evolution.

To demonstrate the utilization of the BAC library, we developed a sequence tagged site (STS) marker for the $d w a r f E(d w E)$ locus. The mutant generally grows only to $40-60 \mathrm{~cm}$ in height and exhibits an increased numbers of branches (Ohnishi and Nagakubo, 1982; Ohnishi, 1990). Dwarfism is an important morphological feature from a breeding viewpoint and its molecular characterization has great agricultural impact, as dwarf crops show lodging resistant and tend to be responsive to fertilizer inputs (Gale and Youssefian, 1985; Khush, 1999). Furthermore, the $d w E$ locus is tightly linked to the selfincompatible complex $(S)$ locus (Ohnishi and Ohta, 1987), while neither of the other five dwarf loci nor any other useful phenotypic loci known are linked to and thus the current study has provided essential tools for the positional cloning of the $S$ locus as well.

\section{MATERIALS AND METHODS}

Plant materials Common buckwheat is a distylous self-incompatible species, consisting of short-styled and long-styled plants. This trait is mainly controlled by a single genomic region, the so called self-incompatibility complex or $S$ gene, where short-styled plant is heterozygote $(S s)$ and long-styled plant is recessive homozygote (ss) (Sharma and Boyes, 1961). Since limited genetic heterogeniety among BACs is desirable while constructing contigs from overlapping clones, a breeding experiment was conducted as shown in Fig. 1, where a pair of short-styled normal plant (strain number: XIF1999) and
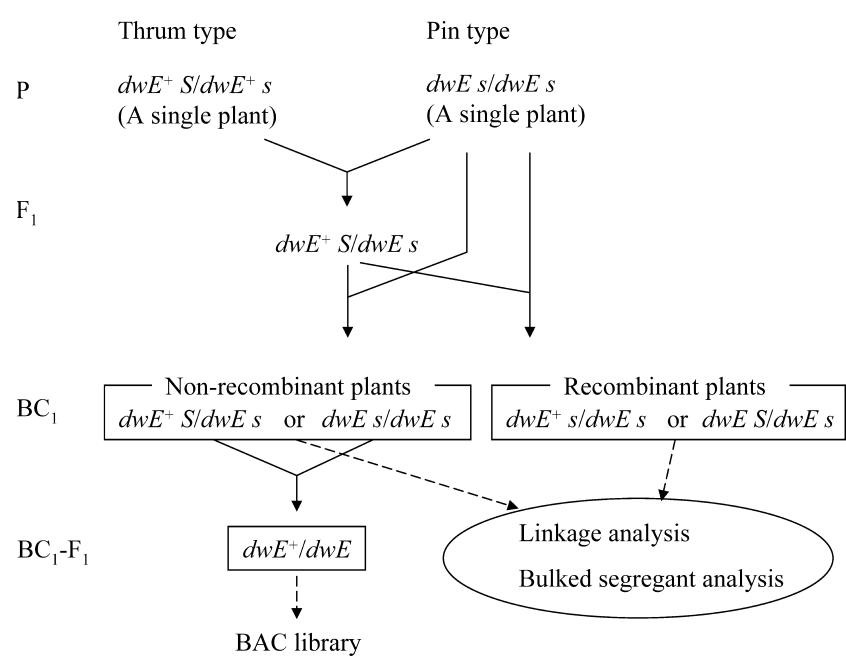

Fig. 1. Breeding scheme for the linkage analysis and the source of genomic DNA used for BAC library construction in common buckwheat. long-styled $d w E$ mutant (strain number: $d w \mathrm{E} 1999)$ were crossed at the parental generation. Successive maintenance of a buckwheat plant for a prolonged period by grafting enabled a short-styled $F_{1}$ plant to be backcrossed to the parental long-styled $d w E$ mutant in a green house. Among the plants of the $\mathrm{BC}_{1}-\mathrm{F}_{1}$ generation which were grown, the first few developing leaves were harvested from approximately 50 normal plants, most of which were likely to be of the $S s$ genotype, in order to prepare the genomic DNA for the BAC library construction.

Preparation of high molecular weight DNA By modifying the protocol described in Van Blokland et al. (1994) and Zhang et al. (1995), high molecular weight DNA were prepared as follows: Approximately $10 \mathrm{~g}$ of leaves from the $\mathrm{BC}_{1}-\mathrm{F}_{1}$ plants was frozen in liquid nitrogen, ground into a fine powder, and suspended in $300 \mathrm{ml}$ of washing buffer $(0.15 \%$ 2-Mercaptoethanol (v/v), 0.5\% Triton X (v/v), $0.5 \mathrm{M}$ sucrose, $0.01 \mathrm{M}$ Tris, $0.08 \mathrm{M} \mathrm{KCl,} 0.01 \mathrm{M}$ ethylenediamine tetraacetic acid (EDTA), $1 \mathrm{mM}$ spermidine, $1 \mathrm{mM}$ spermine, $\mathrm{pH} 9.4$ adjusted by $\mathrm{NaOH}$ ). After cooling on ice for $10 \mathrm{~min}$ and removal of the large debris by filtration through eight layers of cheese cloth, the nuclei were collected by centrifugation $(1800 \mathrm{G})$ at $4^{\circ} \mathrm{C}$ for $10 \mathrm{~min}$. The collected pellet was suspended in $30 \mathrm{ml}$ of Buffer $\mathrm{A}(0.15 \%$ 2-Mercaptoethanol (v/v), $10 \mathrm{mM} \mathrm{NaCl}, 10 \mathrm{mM} 2-(\mathrm{N}$ morpholino) ethanesulfonic acid ( $\mathrm{pH}$ 6.0), 5 mM EDTA, $0.15 \mathrm{mM}$ spermine, $0.5 \mathrm{mM}$ spermidine, $0.16 \%$ Triton $\mathrm{X}$ (v/v), $0.25 \mathrm{M}$ Sucrose) and filtered through two layers of miracloth three times. Nuclei collected by centrifugation $(2000 \mathrm{G})$ at $4^{\circ} \mathrm{C}$ for 5 min was then suspended in $20 \mathrm{ml}$ of buffer B ( $6 \mathrm{~g}$ of $5 \mathrm{x}$ buffer A and $45 \mathrm{~g}$ of Percoll). After centrifugation $(3700 \mathrm{G})$ at $4^{\circ} \mathrm{C}$ for $10 \mathrm{~min}, 10 \mathrm{ml}$ of the upper phase layer was added to $30 \mathrm{ml}$ of $\mathrm{HB}$ buffer $(0.01$ M Tris, $0.08 \mathrm{M} \mathrm{KCl,} \mathrm{0.01} \mathrm{M} \mathrm{EDTA,} 1 \mathrm{mM}$ spermidine, 1 $\mathrm{mM}$ spermine, and $\mathrm{pH} 9.4$ adjusted by $\mathrm{NaOH}$ ). Nuclei collected by centrifugation $(2000 \mathrm{G})$ at $4^{\circ} \mathrm{C}$ for 5 min were then suspended in $1 \mathrm{ml}$ of $\mathrm{HB}$ buffer and warmed at 40 $45^{\circ} \mathrm{C}$. After addition of $1 \mathrm{ml}$ of $1 \%$ low melting agarose, the nuclei-agarose mixture was immediately transferred to plug molds (BioRad) and cooled down for solidification. The DNA blocks were subsequently incubated in lysis buffer (0.5 M EDTA, 1\% sodium lauryl sarcosine (w/v), 0.1 $\mathrm{mg} / \mathrm{ml}$ proteinase $\mathrm{K}(\mathrm{w} / \mathrm{v}), \mathrm{pH} 9.1$ adjusted by $\mathrm{NaOH}$ ) at $50^{\circ} \mathrm{C}$ for 24 hours, and were washed once in 0.5 M EDTA ( $\mathrm{pH} 9.1$ ) at $50^{\circ} \mathrm{C}$ for one hour and once in $0.05 \mathrm{M}$ EDTA ( $\mathrm{pH}$ 8.0) on ice for one hour. Finally the DNA blocks were washed with $1 \mathrm{x}$ TE containing $0.1 \mathrm{mM}$ Phenylmethylsulfonyl fluoride (PMSF) and later with TE buffer, and kept at $4^{\circ} \mathrm{C}$ until the library construction.

BAC library construction The BAC library was constructed as follows (see also Amemiya et al., 1996): After being immersed in $\mathrm{MboI}$ equilibration buffer $(100 \mathrm{mM}$ $\mathrm{NaCl}, 1 \mathrm{mM}$ DTT, $50 \mathrm{mM}$ Tris, $\mathrm{pH} 7.9)$ at $4^{\circ} \mathrm{C}$ over night, 
three DNA agarose blocks (per each experiment for a given concentration of $\mathrm{MboI}$ which was added later) were cut into small pieces, transferred into a new tube containing $M b o \mathrm{I}$ equilibration buffer (adjusted to $1 \mathrm{ml}$ ), and kept on ice for $30 \mathrm{~min}$. Then, 10 units, 20 units or 40 units of MboI (New England Bio Labs) were added and the tubes were kept on ice for 30 min with occasional swirling to promote the penetration of the restriction enzymes into the DNA beads. After addition of $10 \mu \mathrm{l}$ of $1 \mathrm{M} \mathrm{MgCl}_{2}$ (final concentration $10 \mathrm{mM}$ ), the tubes were left on ice for $30 \mathrm{~min}$ and incubated later at $37^{\circ} \mathrm{C}$ for $30 \mathrm{~min}$ to partially digest the DNA, followed by immediate cooling on ice and replacement of the buffer with 0.5 M EDTA to stop the restriction enzyme reaction. After replacing the $0.5 \mathrm{M}$ EDTA solution with 1/2x TBE buffer, the DNA beads that had been treated with the three different concentration of $M b o \mathrm{I}$ were mixed together and transferred onto a $1 \%$ pulse-field certified agarose (BioRad) gel in 1/2x TBE. Electrophoresis were then carried out with a CHEF mapper (BioRad) first by a trash run (three times of block 1 : $5 \mathrm{v} / \mathrm{cm}$, state $1120^{\circ}$, state $2-120^{\circ}, 4$ hours, and block 2 : $5 \mathrm{v} / \mathrm{cm}$, state $160^{\circ}$, state $2-60^{\circ}, 4$ hours) and later by a standard run (two state, $6 \mathrm{v} / \mathrm{cm}, 120^{\circ}, 16$ hours, initial switching time 0.1 sec- final switching time $40 \mathrm{sec}$ ) with a change of buffer between the runs. Partially digested genomic DNA, obtained by electoelution of $\sim 80-120 \mathrm{~kb}$ fragments excised from the gel and subsequent enrichment by microcon (Millipore), was ligated to a Copy Control pCC1BAC vector (Epicentre) by T4 DNA ligase (New England Bio Labs) at $16^{\circ} \mathrm{C}$ over night. After digestion of the ligase by protenase $\mathrm{K}$, inactivation of the protenase $\mathrm{K}$ by PMSF, and desalting/cleaning by drop dialysis against $1 / 2 \times \mathrm{TE}$, the ligated products were transfected into Electromax T1 phage resistant DH10B E. coli cells (Invitrogen) utilizing a Micropulser (Bio Rad). Transformed $E$. coli were incubated in a SOC medium containing 5-10\% glycerol at $37^{\circ} \mathrm{C}$ for about one hour, immediately frozen in ethanol with dry ice, and kept at $-80^{\circ} \mathrm{C}$ until colony picking. Colony picking was later carried out by using a Genetix Qpix2 colony picker utilizing blue/white colony selection. Each picked colony was transferred into a 384-well microtiter dish (containing LB medium with chloramphenicol (10 $\mu \mathrm{g} / \mathrm{ml})$ and $10 \%$ glycerol) one by one, and cultured at $37^{\circ} \mathrm{C}$ overnight. After counting the number of wells in which transformed bacteria were grown, the arrayed library in the microtiter dishes was kept at $-80^{\circ} \mathrm{C}$ for preservation.

Characterization of the BAC library A single BAC was selected from every three microtiter dishes to check its insert size. DNA was isolated for 123 BACs by an alkaline lysis method (Amemiya et al., 1996) and was digested by NotI restriction enzyme, which excised inserts by cutting at both ends of the CopyControl pCC1BAC vector (Epicentre). Pulsed field electrophoresis was car- ried out using a BioRad CHEF mapper (Auto-algorithm, $5 \mathrm{~kb}-250 \mathrm{~kb}$ separation, $0.5 \mathrm{x}$ TBE at $14^{\circ} \mathrm{C}, 1.0 \%$ Pulse Field Certified Agarose). The gels, stained with ethidium bromide, were analyzed with a FluorImager SI (Molecular Dynamics) and the sizes of the Not I fragments were estimated using Fragment Analysis software (Molecular Dynamics).

Library screening PCR based screening was conducted to characterize the constructed library. AGAMOUS(AG), FLORICAULA/LEAFY(FLO/LFY), and Rubisco large subunit $(r b c L)$ were screened, where primers were designed from the nucleotide sequences of Nishimoto et al. (2003) for $A G$ and FLO/LFY, and Yasui and Ohnishi (1996) for $r b c L$. Preliminary genomic Southern hybridization analyses indicated that the two nuclear genes $A G$ and $F L O / L F Y$ were likely to be single copy genes (Yasui et al. unpublished). The conditions for PCR were as follows: $A G, 5$ ' primer: GCTTGGAAGAATGGCCTCAAAACAA, 3' primer: TGCAAGGTTCGAATCTGGTTTCTCA, initial denaturation $94^{\circ} \mathrm{C}$ for $3 \mathrm{~min}, 35$ cycles of $94^{\circ} \mathrm{C}$ for $30 \mathrm{sec}, 66^{\circ} \mathrm{C}$ for $10 \mathrm{sec}$, and $72^{\circ} \mathrm{C}$ for $30 \mathrm{sec}$, final extension $72^{\circ} \mathrm{C}$ for $3 \mathrm{~min}$; $F L O / L F Y$, 5 ' primer: GCAACCGCCGCTACATCTCTCAAC, 3' primer: TGCGTCAATGTCCCAACCTT, initial denaturation $94^{\circ} \mathrm{C}$ for $2 \mathrm{~min}, 30$ cycles of $94^{\circ} \mathrm{C}$ for $30 \mathrm{sec}, 58^{\circ} \mathrm{C}$ for $30 \mathrm{sec}$, and $72^{\circ} \mathrm{C}$ for 2 min, final extension $72^{\circ} \mathrm{C}$ for $5 \mathrm{~min}$; $r b c L, 5^{\prime}$ primer: ATTCATTCCGGTACTGTAGT, 3' primer: TTTGATTTCCTTCCATACTTC, initial denaturation $94^{\circ} \mathrm{C}$ for $2 \mathrm{~min}, 30$ cycles of $94^{\circ} \mathrm{C}$ for $30 \mathrm{sec}, 58^{\circ} \mathrm{C}$ for $30 \mathrm{sec}$, and $72^{\circ} \mathrm{C}$ for 30 sec, final extension $72^{\circ} \mathrm{C}$ for $3 \mathrm{~min}$.

The BAC DNA prepared en mass for each microtiter dish was used for two-rounds of PCR screening, where the templates for the first and second round of PCR screening were the BAC DNAs pooled from multiple (six or eight) microtiter dishes and individual microtiter dishes, respectively, and a second round of PCR screening was conducted only for those microtiter dishes whose first PCR screening was successful. Once a positive result was obtained for a given microtiter dish, a third PCR screening was conducted using two dimensional pools of BACs as templates to identify the address of the PCR positive $\mathrm{BAC}(\mathrm{s})$ on the microtiter dish. With respect to screening of the $r b c L$ gene, almost all microtiter dishes examined contained $r b c L$ positive BACs. Therefore, only a representative microtiter dish (\#180) randomly chosen was examined in detail to identify the address of the BACs and to count the number of positive clones in the microtiter dish.

For clones identified by PCR screening, isolated plasmid DNA was digested by NotI restriction enzyme and pulsed field electrophoresis was carried out with a BioRad CHEF mapper (Auto-Algorithm, $5 \mathrm{~kb}-250 \mathrm{~kb}$ or 1-250 kb separation, $0.5 \mathrm{x}$ TBE at $14^{\circ} \mathrm{C}, 1.0 \%$ Pulse Field Certified Agarose) to examine the insert sizes. 
Linkage analysis AFLP markers (Vos et al., 1995) linked to the $d w E$ and $S$ genes were identified by bulked segregant analysis (Michelmore et al., 1991). Approximately $10 \mathrm{mg}$ of leaf tissue from individual $\mathrm{BC}_{1}$ plants were used to extract DNA in bulk. Fifty short-styled normal plants and 50 long-styled $d w E$ plants were bulked separately. To identify AFLP markers specific to the $d w E^{+} S$ haplotype which were present for short-styled normal plants but absent for long-styled $d w E$ plants, 256 primer combinations (Mse-CNN x Eco-ANN) were examined, where AFLP reactions were carried out according to the manufacturer's protocols (AFLP Analysis Kit, Life Technologies). After electrophoresis on a 5\% denaturing polyacrylamide gel, amplified DNA fragments were visualized by DNA silver staining kit (Promega). For AFLP markers present only among the short-styled normal plants, the segregation patterns were analyzed for phenotypic recombinants of the $\mathrm{BC}_{1}$ generation in order to infer the linkage relationships of the AFLP markers to each other as well as to the $d w E$ and $S$ loci.

Conversion of an AFLP marker to an STS marker To convert an AFLP marker into a more reliable STS marker, additional amplification with 16 primer pairs was conducted by adding one extra selective base (either A, C, G, or T) to the 3' end of a pair of primers. Selected bands of interest, visualized by silver staining, were excised from a polyacrylamide gel using a razor blade and incubated in $50 \mu \mathrm{l}$ of distilled water at $98^{\circ} \mathrm{C}$ for 3 min. The elution was used for the PCR template with the same primer set for further amplification. The conditions for the PCR was as follows: initial denaturation $94^{\circ} \mathrm{C}$ for $2 \mathrm{~min}, 30$ cycles of $94^{\circ} \mathrm{C}$ for $30 \mathrm{sec}, 58^{\circ} \mathrm{C}$ for 30 sec, and $72^{\circ} \mathrm{C}$ for $30 \mathrm{sec}$, final extension $72^{\circ} \mathrm{C}$ for $3 \mathrm{~min}$. The PCR products were ligated to a pGEM-T vector according to the manufacturer's protocols (Promega). Purified plasmid DNA was used in the DNA sequencing reactions with Taq Dye Deoxy Terminator Kit (Applied Biosystems). Electrophoresis and data collection were carried out on a 373 DNA sequencer (Applied Biosystems). The nucleotide sequence of the STS primers were designed from those obtained by DNA sequence and used for PCR screening of the BAC library. The conditions for the PCR were as follows: \#115-FW primer: 5'-AGGAGAGCGATGTTGTTCTA-3', \#115-RV primer: 5'-CCGGATCTAAAATTTATTGG-3', initial denaturation $94^{\circ} \mathrm{C}$ for 2 min, 30 cycles of $94^{\circ} \mathrm{C}$ for $30 \mathrm{sec}, 55^{\circ} \mathrm{C}$ for $30 \mathrm{sec}$, and $72^{\circ} \mathrm{C}$ for $30 \mathrm{sec}$, final extension $72^{\circ} \mathrm{C}$ for $3 \mathrm{~min}$.

\section{RESULTS AND DISCUSSION}

Construction and characterization of library A buckwheat BAC library was constructed based on the method described in Amemiya et al. (1996) with modification of some of the procedures: high molecular weight DNA was obtained from the young leaves using a method which includes a percoll gradient centrifugation step to enrich the nuclei fraction. The DNA plugs were cut into small pieces to facilitate the penetration of restriction enzyme into the gel matrix. A trash run was included during the electrophoresis to remove the smaller fragments from the agarose gel and to reduce the number of BACs with a smaller insert (C. T. Amemiya, personal communication). Electroelution was used to purify partially-digested DNA out of the excised gel fragments (Strong et al., 1997).

A total of 142,080 BACs from white colonies on the LB agar plates containing chloramphenicol $(12.5 \mu \mathrm{g} / \mathrm{ml}), \mathrm{X}$ gal $(0.002 \%)$ and IPTG $(0.2 \mathrm{mM})$ were transferred into 370 plates of 384-well microtiter dishes, among which 142,005 clones were successfully grown. The distribution of the insert sizes for the BAC library was investigated by examining 123 BACs which were systematically selected. The results are shown in Fig. 2, where the insert size ranged from 26 to $233 \mathrm{~kb}$. These results excluded four clones $(3.2 \%)$, one clone with a vector artifact and three clones with no or small, if any, inserts. Approximately one half of the clones had inserts ranging from $50 \mathrm{~kb}$ to $90 \mathrm{~kb}$ in length. The average insert size was estimated at $\sim 76 \mathrm{~kb} \pm 3 \mathrm{~kb}$ after taking all 123 BACs into account. Among the 123 BACs digested by Not $\mathrm{I}$, only six had more than two Not I fragments in addition to the vector fragments. In total, only seven $N o t$ I sites were detected among the $\sim 9 \mathrm{Mbp}$ region which consisted of randomly distributed genomic regions encoded in 123

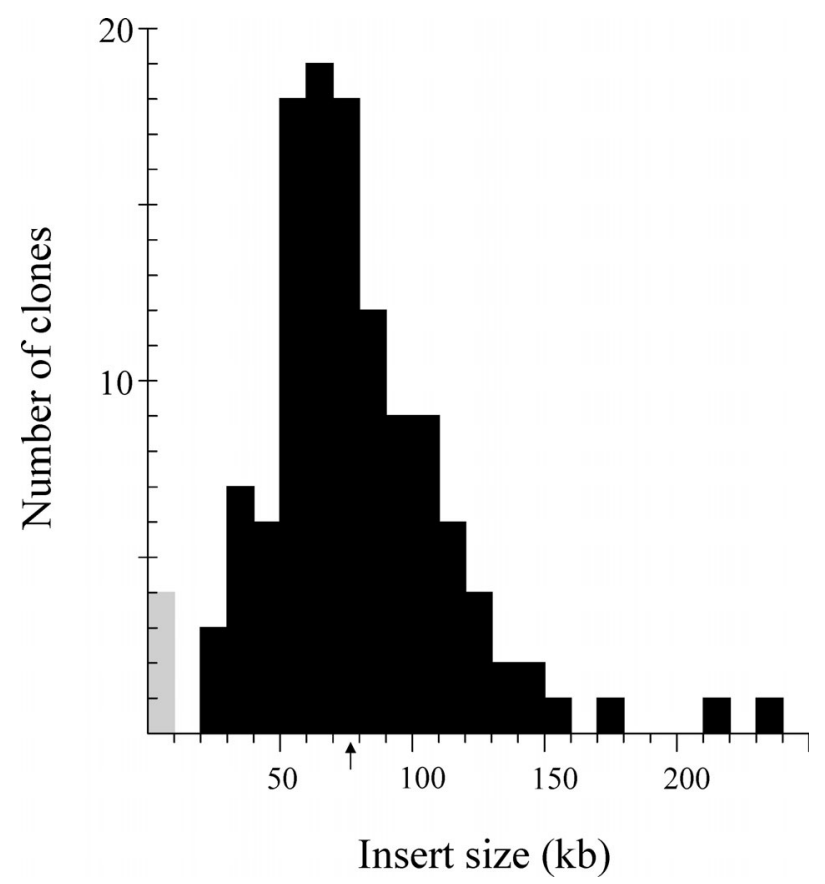

Fig. 2. Size distribution of 123 BAC inserts. Gray bar indicates the number of clones with vector artifact or no (or small) insert. Arrow indicates the average insert size ( 76 kb). 
BACs. Therefore, NotI sites appear to be infrequent, if one considers that $\sim 137$ sites were expected for a $9 \mathrm{Mbp}$ region under the assumption of equal frequency and random distribution of the four kinds of nucleotides.

PCR screening and library coverage In order to examine the number of clones containing chloroplast DNA (cpDNA), we screened for the $r b c L$ gene in one plate (\#180) and found 10 out of 384 clones containing the $r b c L$ gene. This indicated that the BAC library contained approximately $3,700( \pm 1155)$ equivalents of the chloroplast genome, which corresponds to $0.58( \pm 0.18) \times 10^{9} \mathrm{bp}$ as the size of the buckwheat chloroplast genome is approximately $155.5 \mathrm{~kb}$ (Kishima et al., 1995). When it was considered that the total size of the inserts for the constructed BAC library was approximately $10.8( \pm 0.4) \times$ $10^{9} \mathrm{bp}$, the BAC library was estimated to represent 7.6 $( \pm 0.3)$ equivalents of the nuclear genome, since the haploid genome DNA content was estimated to be $1340 \mathrm{Mbp}$ (Nagano et al., 2000). This could be, however, an overestimate of the genomic coverage, since some clones may contain some parts of the mitochondrial genome. To further investigate the utility of the BAC library, we screened the library for two nuclear genes, i.e., $A G$ and FLO/LFY and obtained 7 and 9 positive clones with an average insert size of $92 \mathrm{~kb}$ and $89 \mathrm{~kb}$ respectively (Table 1). The numbers of clones found are roughly consistent to the estimated library coverage.

Usage of the constructed BAC library BAC libraries have been indispensable tools for physical mapping or genome sequencing of complex organisms and have been constructed for monocots and dicots of commercial importance. In addition to the libraries made by individual researchers, recent efforts have been directed in making high quality large insert libraries of public resources for representative plant groups (e.g. www.greenbac.org). So far large insert libraries have been constructed for a wide variety of species, covering the evolutionary diversified groups of angiosperms. Common buckwheat belongs to Polygonales, one of the core tricolpates that diverged from other major core tricolpates, such as rosids or asterids at an early stage in angiosperm evolution (e.g. Judd et al., 1999). The BAC libraries of buckwheat will provide useful resources for studying the basic genomic differences among core tricolpates and the early evolution of core tricolpates.

As mentioned earlier, large insert clones, such as BACs, are useful for map-based cloning of genes, which utilize linkage relationship of genes to identify specific genes of unknown primary structure. Extensive analysis of AFLP markers using the cross between $F$. esculentum and $F$. homotropicum (Yasui et al., 2004) has shown that the buckwheat genome consists of eight linkage groups with approximately a $510 \mathrm{cM}$ region, which gave a rough estimate of $2.6 \mathrm{Mb} / \mathrm{cM}$, even though the recombination ratio may vary among regions and may depend on other experimental factors such as the type of cross. Nonetheless it is highly possible that, if any, genetic markers less than $130 \mathrm{~kb}$ away from the gene of interest can be found by linkage analysis of 2000 backcross progenies, unless recombination is suppressed in the region studied. Despite the relatively small average insert size, the BAC library constructed here may be valuable for map-based cloning of genes, since it was feasible to obtain $>2000$ backcross progeny in buckwheat with ease. In most cases, a few steps of chromosomal walking of the BAC library could identify a clone containing the gene of interest.

In order to conduct chromosome walking successively, the level of polymorphism should be kept to a minimum among the haplotypes present in the genomic library. In this respect, the library constructed here was suited as it was derived from, at most, four different haplotypes which were present at the parent generation, even though a large number of individuals of the $\mathrm{BC}_{1}-\mathrm{F}_{1}$ generation were used to isolate the genomic DNA. Regarding the $d w E$ locus (and its closely linked region which includes the $S$ locus), the situation was even better, since only three out of four genes of the parent generation were present. Considering the fact that the $d w E$ mutant was originally found in a single natural Japanese population,

Table 1. Result of PCR screening of the BAC library

\begin{tabular}{|c|c|c|}
\hline Gene & \# of clones & Address of clones (Insert size) \\
\hline$A G$ & 7 & $\begin{array}{l}\text { 34I24 (103 kb), 99G5 (68 kb), 170P23 (115 kb) } \\
\text { 179J7 (89 kb), 189D8 (113 kb), 356I8 (57 kb) } \\
\text { 363P17 (76 kb) }\end{array}$ \\
\hline$F L O / L F Y$ & 9 & $\begin{array}{l}\text { 17J15 }(20 \mathrm{~kb}), 108 \mathrm{H} 8^{\mathrm{a}}(89 \mathrm{~kb}), 137 \mathrm{~F} 16(76 \mathrm{~kb}) \\
161 \mathrm{M} 20(85 \mathrm{~kb}), 168 \mathrm{H} 2^{\mathrm{a}}(117 \mathrm{~kb}), 173 \mathrm{~L} 17^{\mathrm{a}}(33 \mathrm{~kb}) \\
201 \mathrm{~N} 15^{\mathrm{a}}(100 \mathrm{~kb}), 203 \mathrm{O} 7(110 \mathrm{~kb}), 343 \mathrm{~L} 21^{\mathrm{a}}(150 \mathrm{~kb})\end{array}$ \\
\hline \#115 marker & 4 & $\begin{array}{l}\text { 44E18 }(63 \mathrm{~kb}), 132 \mathrm{~B} 8(89 \mathrm{~kb}), 230 \mathrm{~L} 2(88 \mathrm{~kb}) \\
320 \mathrm{G} 13(97 \mathrm{~kb})\end{array}$ \\
\hline
\end{tabular}

${ }^{\mathrm{a}}$ The clones possess an internal NotI site. 
it was also possible that the two alleles of the parental long-styled $d w E$ plant were identical in descent. If so, the genomic library may consist of only two haplotypes for the region closely linked to the $d w E$ and $S$ loci.

A BAC library has already been made for $F$. homotropicum, a close relative of common buckwheat (Nagano et al., 2005), although its limited genomic coverage restricts its application for making contigs over an extended region (Aii et al., 2004). A smaller genome size and increased genetic homogeneity due to the selfing nature of $F$. homotropicum make the species desirable for making a BAC library. Nonetheless, it may be less informative on characterizing the heteromorphic selfincompatibility system, since the system has been lost in the lineage of $F$. homotropicum while many other species in the genus Fagopyrum have retained the system for a long evolutionary time. In this respect, the BAC library of $F$. esculentum constructed herein should become a valuable resource for studying the heteromorphic selfincompatibility system, and, together with the genomic library of $F$. homotropicum, it will provide basic knowledge on the evolutional change of the reproductive systems in the genus Fagopyrum.

Inference of genetic map around the $d w E-S$ region and identification of BACs containing a STS marker closely linked to the $\boldsymbol{d w E}$ locus During the crossing experiment, we observed the plant height and flower type of approximately 2800 plants of the $\mathrm{BC}_{1}$ generation. Among them, only 10 plants exhibited a recombinant phenotype: six were long-styled normal plants and four were short-styled $d w E$ plants (Table 2 ). The probability of double recombination within the $d w E-S$ region was, therefore, quite low or negligible, and genetic distances between a DNA marker and $d w E$ or $S$ locus could be estimated from segregation patterns (presence or absence of a DNA marker) among the 10 recom- binant plants, for the DNA markers whose close proximity to the $d w E$ or $S$ loci were once ascertained. This approach has liberated isolation and examination of genomic DNAs from $\sim 2800$ plants.

When comparing the AFLP banding pattern observed for the two separate bulks, we found 81 AFLP markers specific to the bulks of short-styled normal plants. It was also noted that 81 AFLP markers were classified into eight groups according to the segregation patterns observed among 10 recombinants. Among the eight groups, it was obvious that the AFLP markers belonging to group II and group VII were located in a close vicinity to the $d w E$ and $S$ loci, respectively, as no recombinant was observed. It is noteworthy to observe that the number of AFLP markers belonging to group VII was much larger than that for group II. This may represent reduced recombination at the $S$ locus region as compared to that at the $d w E$ locus region and/or an older origin of the distinct alleles with a larger number of polymorphic sites at the $S$ locus than at the $d w E$ locus. It is also possible that different GC/AT contents may have caused the regional variation of the number of detectable AFLP markers between the two regions. Next, the AFLP markers belonging to group I or group III were inferred to be proximate to the $d w E$ region, just outside of the area represented by group II, since only one recombinant plant (R9 and R3, respectively) was observed between the AFLP marker and $d w E$ loci. Retrospectively, nine recombinant plants were observed between the AFLP marker and $S$ loci for both groups. These numbers were intriguing and one might wonder if the two groups of AFLP markers were locating at the same region $(d w E-0.04 \mathrm{cM}$ - AFLP marker $-0.32 \mathrm{cM}-S$ ) or if the results were due to artifact since they seemed to be conflicting each other. More likely scenario we considered was, however, that some recombinants were results of double recombination with additional recombination point locating outside the $d w E$ -

Table 2. Recombinants and AFLP markers found in the linkage analysis ${ }^{\mathrm{a}}$

\begin{tabular}{|c|c|c|c|c|c|c|c|c|c|c|c|c|c|}
\hline \multirow{3}{*}{$\begin{array}{l}\text { AFLP } \\
\text { Pattern }\end{array}$} & \multirow{3}{*}{$\begin{array}{l}\text { Number of } \\
\text { AFLPs } \\
\text { (Marker\#) }\end{array}$} & \multicolumn{2}{|c|}{ Non-recombinants } & \multicolumn{10}{|c|}{ Recombinants } \\
\hline & & \multirow{2}{*}{$\begin{array}{l}\text { Short- } \\
\text { styled } \\
\text { Normal } \\
\text { (bulk) }\end{array}$} & \multirow{2}{*}{$\begin{array}{l}\text { Long- } \\
\text { styled } \\
d w E \\
\text { (bulk) }\end{array}$} & \multicolumn{6}{|c|}{ Long-styled Normal } & \multicolumn{4}{|c|}{ Short-styled $d w E$} \\
\hline & & & & $\mathrm{R} 1$ & $\mathrm{R} 6$ & R5 & R10 & $\mathrm{R} 7$ & R9 & $\mathrm{R} 2$ & $\mathrm{R} 8$ & $\mathrm{R} 4$ & R3 \\
\hline I & 9 & + & - & + & + & + & + & + & - & - & - & - & - \\
\hline II & 13 & + & - & + & + & + & + & + & + & - & - & - & - \\
\hline III & $2(\# 58, \# 115)$ & + & - & + & + & + & + & + & + & - & - & - & + \\
\hline IV & $2(\# 71, \# 116)$ & + & - & + & + & + & + & + & + & - & - & + & + \\
\hline $\mathrm{V}$ & $2(\# 40, \# 57)$ & + & - & + & + & + & - & - & - & - & + & + & + \\
\hline VI & $1(\# 9)$ & + & - & + & - & - & - & - & - & + & + & + & + \\
\hline VII & 38 & + & - & - & - & - & - & - & - & + & + & + & + \\
\hline VIII & 14 & + & - & - & - & - & - & + & - & + & + & + & + \\
\hline
\end{tabular}

${ }^{\text {a }}$ Plus (+) and minus (-) signs indicate the presence and absence of AFLP markers, respectively. 
$S$ region and the AFLP markers for one group were located between the $d w E$ and $S$ loci and those for the other groups were located outside the $d w E-S$ region. Since approximately 2800 plants were examined for recombination within the $d w E-S$ region at the phenotypic level but only 60 plants, i.e., 10 recombinants and 50 plants used for bulk, were examined for recombination outside the $d w E-S$ region at the DNA level, the number of AFLP markers for the group located between the $d w E$ and $S$ loci was expected to be much less than for the group located outside the $d w E-S$ region. Therefore, the AFLP markers belonging to group I and group III were inferred to be located outside the $d w E-S$ region and between the $d w E$ and $S$ loci, respectively. Nonetheless, as shown in later, the presence/absence of AFLP markers for each recombinant was consistently explained by the inferred order of AFLP markers, once double-recombination was assumed to occur only for R9 (and R7). The same reasoning was also applicable to the groups VI and VIII. Between the AFLP markers belonging to groups IV and $\mathrm{V}$, those belonging to group IV were inferred to be located in the region next to the group II $(d w E)$ - group III region, since only two recombinants (R3 and R4) were observed for group IV, whereas six recombinants (R3, R4, R7, R8, $\mathrm{R} 9$, and R10) were observed for group $\mathrm{V}$, between each group and the $d w E$ locus. Finally, the order of the AFLP markers was deduced as presented in Fig. 3. The probable recombination breakpoints and map distance among the $d w E$ locus, $S$ locus and AFLP markers are also presented in Fig. 3.

Even though 13 and 38 AFLP markers, belonging to group II and group VII, were likely to surround the $d w E$ and $S$ loci respectively, some of the AFLP markers were located far from the $d w E$ or $S$ loci, since we used only 50 bulked plants and 10 recombinant plants for the examination of recombinants outside of $d w E-S$ region. For example, the AFLP markers belonging to group II locate at $-1.67(1 / 60) \mathrm{cM} \sim+0.035(1 / 2800) \mathrm{cM}$ region from the $d w E$ locus, where the region located toward the $S$ locus is shown in positive numbers. In this respect, the AFLP markers belonging to group III were more useful markers locating at $+0.035 \sim+0.070 \mathrm{cM}$ and were certain to be in close vicinity to the $d w E$ locus.

So far, two (\#58 and \#115) and one (\#9) AFLP markers were identified to be tightly linked to the $d w E$ locus and the $S$ locus, respectively (Fig. 3). Among them, \#115 was successfully converted to a STS marker, where the PCR amplification using primers designed for the STS marker generated three DNA fragments (290 bp, $320 \mathrm{bp}$ and 390 bp) for normal height plants and one DNA fragment (290 bp) for dwarf plants. It was probable that the three bands detected in normal plants were amplified from repeat variants on a narrow genomic region linked to $d w E^{+}$allele, because these three bands were amplified even from individual BACs isolated (Fig. 4). PCR screening for the STS marker \#115 identified four BACs with the three DNA fragments (average insert size $\sim 84$ $\mathrm{kb}$ ) (Table 1). Since this STS marker was developed to short-styled normal plant but not long-styled dwarf plant, a $d w E^{+} S$ haplotype but not a $d w E s$ haplotype is expected to contain the marker. Therefore, the number of positive clones was expected to be one-half of the genomic coverage. Indeed, the number of clones obtained with the STS marker (i.e., four) was consistent with one-half of the genomic coverage (7-8x) of the BAC library. This illustrates the usefulness of the library even for chromosome walking with haplotype specific markers.

Positional cloning of the $\boldsymbol{d w E}$ and $\boldsymbol{S}$ genes In the present study, a STS marker (\#115) tightly linked to the $d w E$ locus was developed and four clones (44E18, 132B8, 230L2, and 320G13) were successfully obtained by PCR based screening. The map distance between the $d w E$ locus and \#115 marker was estimated to be $0.04 \mathrm{cM}$. One

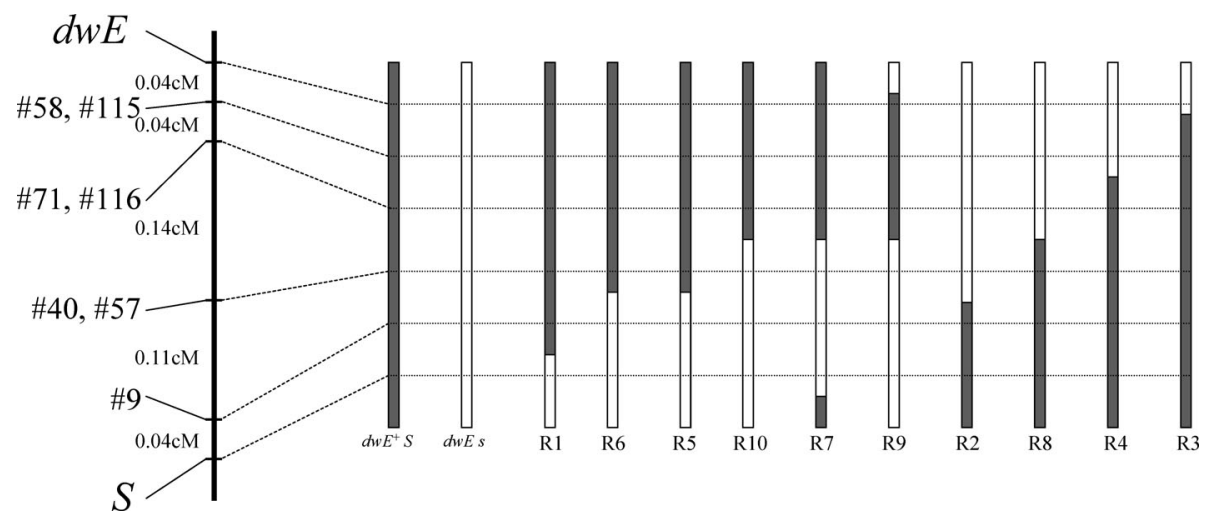

Fig. 3. The linkage map for AFLP markers at the $d w E-S$ locus region and deduced recombination breakpoints of ten recombinants. Hatched bars indicate the region derived from $d w E^{+} S$ haplotype and blank bars indicate the region derived from $d w E s$ haplotype. Dashed lines indicate approximate position of AFLP markers, $S$, and $d w E$ loci. 


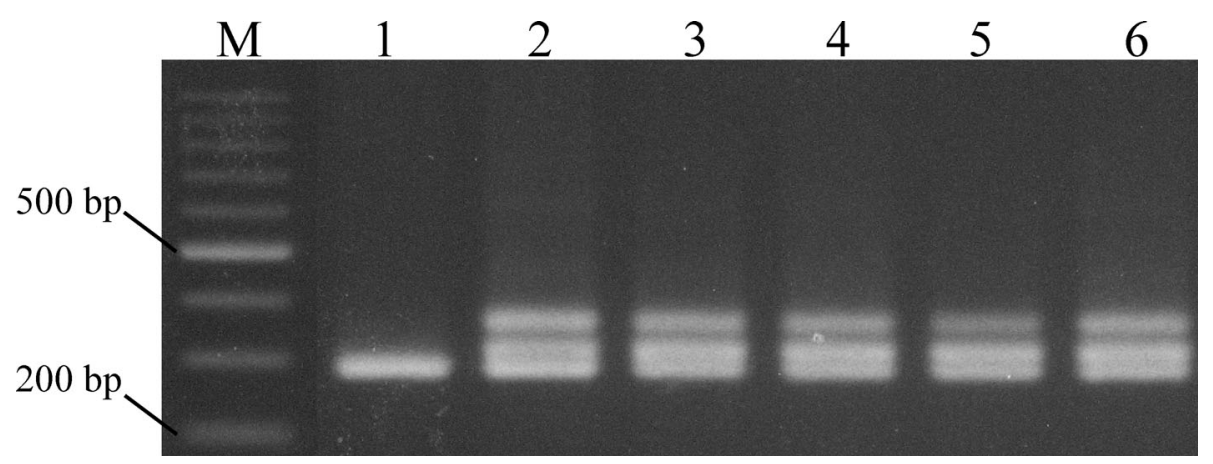

Fig. 4. PCR products generated by using STS marker \#115. Total DNA extracted from a normal plant (lane 1), and a $d w E$ mutant plant (lane 2) were used as DNA template. DNA of 44E18 (lane 3), 132B8 (lane 4), 230L2 (lane 5), and 320G13 (lane 6) BACs were also used as templete. The DNA marker (100 bp ladder, New England Bio Labs) was shown on the left (lane M).

of BACs identified has been subjected to shotgun sequence and characterization of the identified genes are in progress. Recent molecular studies of various plants have found some dwarf genes playing an important role during the plant hormone signaling pathway (e.g., gai for Arabidopsis, Peng et al., 1997; $\max 3$ for Arabidopsis, Booker et al., 2004; $u z u$ for barley, Saisho et al., 2004; $d 11$ for rice, Tanabe et al., 2005). Among them, the $\max 3$ gene encoding for carotenoid cleavage dioxigenase is of specific attention, since $\max 3$ mutants exhibit not only short statue but also an increased number of branches as also observed in $d w E$ mutants. However no gene homologous to the max3 gene has yet been identified from the sequences obtained so far.

The heteromorphic self-incompatibility system in buckwheat has been postulated to consist of a gene complex containing at least five genes, $G$ (style length), $I^{S}$ (style incompatibility), $I^{P}$ (pollen incompatibility), $P$ (pollen size), and $A$ (anther height) (Shrama and Boyes, 1961). A recent experiment, conducted by Matsui et al. (2003), also supported the hypothesis and suggested that $F$. homotropicum, an unusual self pollinating species, has arisen by a past recombination event in the $S$ gene complex. In order to clarify the molecular mechanism of the heteromorphic self-incompatibility system and its evolution, a large insert size library with enough genomic coverage is necessary to clone the entire $S$ locus, for both $S$ and $s$ haplotypes. We are currently conducting a large scale chromosome walking to uncover the molecular basis of self-incompatibility system in buckwheat using the BAC library constructed here.

In summary, the library constructed herein represents the first large insert genomic library for $F$. esculentum and we are now in position for pursuing the positional cloning of the causative gene of $d w E$ mutation and the genes in the heteromorphic self-incompatible complex of the species.

We thank Chris T. Amemiya for suggestions on constructing the library, N. Iwabe and T. Miyata for the use of the colony picker, N. Lu and the assistants at Kade Research Ltd for helping the generation of mapping populations, and two anonymous reviewers for valuable comments. This study was supported by a Research Project Grant at the Hayama center for advanced studies at the Graduate University for advanced studies (Sokendai) and a Grant-in-aid for Scientific Research from the Ministry of education, culture, sports, science and technology, Japan (\#18380006).

\section{REFERENCES}

Aii, J., Nagano, M., Kawasaki, S., and Adachi, T. (2004) Centromeric location of the $S$-locus in buckwheat. Fagopyrum 21, 21-25.

Amemiya, C. T., Ota, T., and Litman, G. W. (1996) Construction of $\mathrm{P} 1$ artificial chromosome (PAC) libraries from lower vertebrates. In: Nonmammalian genomic analysis: a practical guide (eds.: B. Birren, and E. Lai), pp. 223-256. Academic press, San Diego.

Booker, J., Auldridge, M., Wills, S., McCarty, D., Klee, H., and Leyser, O. (2004) MAX3/CCD7 is a carotenoid cleavage dioxygenase required for the synthesis of a novel plant signaling molecule. Curr. Biol. 14, 1232-1238.

Fujimura, M., Minami, Y., Watanabe, K., and Tadera, K. (2003) Purification, characterization, and sequencing of a novel type of antimicrobial peptides, Fa-AMP1 and Fa-AMP2, from seeds of buckwheat (Fagopyrum esculentum Moench.). Biosci. Biotechnol. Biochem. 67, 1636-1642.

Gale, M. D., and Youssefian, S. (1985) Dwarfing genes in wheat. In: Progress in plant breeding (ed.: G. E. Russell), pp. 1-35. Butterworths, London.

Judd, W. S., Campbell, C. S., Kellogg, E. A., and Stevens, P. F. (1999) Plant systematic A phylogenetic approach. Sinauer, Sunderland.

Kawa, J. M., Taylor, C. G., and Przybylski, R. (2003) Buckwheat concentrate reduces serum glucose in streptozotocin-diabetic rats. J. Agric. Food. Chem. 51, 7287-7291.

Khush, G. S. (1999) Green revolution: preparing for the 21st century. Genome 42, 646-655.

Kishima, Y., Ogura, K., Mizukami, K., Mikami, T., and Adachi, T. (1995) Chloroplast DNA analysis in buckwheat species: phylogenetic relationships, origin of the reproductive systems and extended inverted repeats. Plant Sci. 108, 173179.

Konishi, T., and Ohnishi, O. (2006) A linkage map for common 
buckwheat based on microsatellite and AFLP markers. Fagopyrum 23, 1-6.

Konishi, T., Iwata, H., Yashiro, K., Tsumura, Y., Ohsawa, R., Yasui, Y., and Ohnishi, O. (2006) Development and characterization of microsatellite markers for common buckwheat. Breeding Sci. 56, 277-285.

Ma, J. F., Zheng, S. J., Hiradate, S., and Matsumoto, H. (1997) Detoxifying aluminum with buckwheat. Nature 390, 569570.

Matsui, K., Tetsuka, T., Nishio, T., and Hara, T. (2003) Heteromorphic incompatibility retained self-compatible plants produced by a cross between common and wild buckwheat. New Phytologist 159, 701-708.

Michelmore, R., Paran, I., and Kesseli, R. (1991) Identification of markers linked to disease resistance genes by bulked segregant analysis. Proc. Natl. Acad. Sci. USA 88, 9828-9832.

Nagano, M., Aii, J., Campbell, C. G., Kawasaki, S., and Adachi, T. (2000) Genome size analysis of the genus Fagopyrum. Fagopyrum 17, 35-39.

Nagano, M., Aii, J., Campbell, C. G., Adachi, T., and Kawasaki, S. (2005) Construction of a BAC library for the investigation of the $S$ locus in Buckwheat. Fagopyrum 22, 13-20.

Nishimoto, Y., Ohnishi, O., and Hasegawa, M. (2003) Topological incongruence between nuclear and chloroplast DNA trees suggesting hybridization in the urophyllum group of the genus Fagopyrum (Polygonaceae). Genes Genet. Syst. 78, 139-153.

Ohnish, O. (1990) Analyses of genetic variants in common buckwheat, Fagopyrum esculentum Moench: A review. Fagopyrum 10, 12-22.

Ohnishi, O., and Nagakubo, T. (1982) Population genetics of cultivated common buckwheat, Fagopyrum esculentum Moench. II. Frequency of dwarf mutants in Japanese populations. Jpn. J. Genet. 57, 641-650.

Ohnishi, O., and Ohta, T. (1987) Construction of a linkage map in common buckwheat, Fagopyrum esculentum Moench. Jpn. J. Genet. 62, 397-414.

Park, S., and Ohba, H. (2004) Suppressive activity of protease inhibitors from buckwheat seeds against human T-acute lymphoblastic leukemia cell lines. Appl. Biochem. Biotech. 117, 65-74.

Peng, J., Carol, P., Richards, D. E., King, K. E., Cowling, R. J., Murphy, G. P., and Harberd, N. P. (1997) The Arabidopsis GAI gene defines a signaling pathway that negatively regulates gibberellin responses. Genes Dev. 11, 3194-3205.
Pu, F., Mishima, K., Egashira, N., Iwasaki, K., Kaneko, T., Uchida, T., Irie, K., Ishibashi, D., Fujii, H., Kosuna, K., et al. (2004) Protective effect of buckwheat polyphenols against long-lasting impairment of spatial memory associated with hippocampal neuronal damage in rats subjected to repeated cerebral ischemia. J. Pharmaco. Sci. 94, 393-402.

Saisho, D., Tanno, K., Chono, M., Honda, I., Kitano, H., and Takeda, K. (2004) Spontaneous brassinolide-insensitive barley mutants ' $u z u$ ' adapted to East Asia. Breeding Sci. 54, 409-416.

Sharma, K. D., and Boyes, J. W. (1961) Modified incompatibility of buckwheat following irradiation. Can. J. Bot. 39, 12411246

Strong, S. J., Ohta, Y., Litman, G. W., and Amemiya, C. T. (1997) Marked improvement of PAC and BAC cloning is achieved using electroelution of pulsed-field gel-separated partial digests of genomic DNA. Nucleic Acids Res. 25, 3959-3961.

Tanabe, S., Ashikari, M., Fujioka, S., Takatsuto, S., Yoshida, S., Yano, M., Yoshimura, A., Kitano, H., Matsuoka, M., Fujisawa, Y., et al. (2005) A novel cytochrome P450 is implicated in brassinosteroid biosynthesis via the characterization of a rice dwarf mutant, dwarf11, with reduced seed length. Plant Cell 17, 776-790.

Tsuzuki, E., and Dong, Y. (2003) Buckwheat allelopathy: use in weed management. Allelopathy J. 12, 1-11.

Van Blokland, R., Van der Geest, N., Mol, J. N. M., and Kooter, J. M. (1994) Transgene-mediated suppression of chalcone synthase expression in Petunia hybrida results from an increase in RNA turnover. Plant J. 6, 861-877.

Vos, P., Hogers, R., Bleeker, M., Reijans, M., Van de Lee, T., Hormes, M., Frijters, A., Pot, J., Peleman, J., Kuiper, M., et al. (1995) AFLP: a new technique for DNA fingerprinting. Nucleic Acids Res. 23, 4407-4414.

Yasui, Y., and Ohnishi, O. (1996) Comparative study of $r b c L$ gene sequences in Fagopyrum and related taxa. Genes Genet. Syst. 71, 219-224.

Yasui, Y., Wang, Y., Ohnishi, O., and Campbell, C. G. (2004) Amplified fragment length polymorphism linkage analysis of common buckwheat (Fagopyrum esculentum) and its wild self-pollinated relative Fagopyrum homotropicum. Genome 47, 345-351.

Zhang, H. B., Zhao, X., Ding, X., Paterson, A. H., and Wing, R. A. (1995) Preparation of megabase-size DNA from plant nuclei. Plant J. 7, 175-184. 